\title{
Design of Miniaturized Dual-Band Wilkinson Power Divider Using Dual and Cascade $\pi$-Shaped Transmission Lines
}

\author{
Mukesh KUMAR, Susanta Kumar PARUI, Santanu DAS \\ Dept. of Electronics \& Telecommunication Engineering, Indian Inst. of Engineering Science \& Technology, \\ Shibpur-711103, India \\ mukeshnitd415@gmail.com, \{arkapv, santanumdas\}@yahoo.com \\ Submitted November 15, 2017 / Accepted October 12, 2018
}

\begin{abstract}
This paper presents a design of compact dualband Wilkinson power divider (WPD). The cascaded $\pi$ shape and dual transmission lines are used instead of conventional transmission line sections of the reference WPD in order to miniaturize the circuit area. Therefore, $62 \%$ size reduction has been achieved without much affecting the performance of power divider. The insertion-loss of the output ports is within $(3.4 \pm 0.3) \mathrm{dB}$, for the reflection coefficient better than $-15 \mathrm{~dB}$ and isolation better than $18 \mathrm{~dB}$ at the lower frequency band of $1.1 \mathrm{GHz}$. Similarly the insertion-loss is within $(3.4 \pm 0.3) \mathrm{dB}$, for the reflection coefficient better than $-18 \mathrm{~dB}$ and isolation better than $24 \mathrm{~dB}$ at the upper frequency band of $2.55 \mathrm{GHz}$. The proposed WPD is analyzed, fabricated and tested. It is found that the measurement results are in good agreement with the simulated one.
\end{abstract}

\section{Keywords}

Wilkinson power divider, dual-band, cascaded pishaped line, dual transmission line, miniaturization

\section{Introduction}

Nowadays communication industries motivate the researchers to design the microwave components to be operated at multiple frequency bands. Power dividers are one of the important microwave components used for combining and dividing the microwave signals, as a result of which they are used in many microwave subsystems, such as power amplifiers, modulators, antenna arrays and so on [1], [2]. Power divider is a circuit in which input signal is received from one port and outputs are taken from others ports. To achieve equal power division at outputs, Wilkinson power dividers (WPD) are widely used due to their simplest design, impedance matching at all ports and high isolation between output ports. Researchers are giving more attention to design of multi-band WPD. Various methods are available in the literature which offers dualband WPD with improved performance such as, cascading two transmission lines [3], incorporating lumped element $(\mathrm{R}, \mathrm{L}, \mathrm{C})$, but it offers additional parasitic effect especially at high frequency [4-5], stepped impedance [6], adding shunt stubs [7-9], extension of all ports [10], [11], shunt open-stubs with enhanced attenuation characteristics [12], three transmission line sections [13], and simplified approach for three transmission line sections [14] are recommended. However, the circuit size of a power divider becomes large specifically at lower frequencies due to the structural dependence on the quarter wave length $(\lambda / 4)$ line. Many researchers have proposed several techniques to reduce the overall size of the microwave circuits (power divider and couplers) [15-22]. In [15] parallel coupled line, composite right-/left-handed (CRLH) transmission line [16], electromagnetic band-gap (EBG) structure [17], [18], defected ground structure (DGS) [19], high-low impedance resonator [20], cascaded $\pi$-shape transmission lines [21], and dual transmission line [22], are used for miniaturization as well as harmonic suppression of microwave circuits. Recently dual-band PD was efficiently designed with high selectivity [23], based on port extension [24], combination of T-junction and step impedance line [25], however all the designs are having larger circuit size. The major drawback of using CRLH transmission line based on complementary split ring resonator (CSRR) and the DGS is that they need additional etching technique in fabrication process, and causes back radiation which affects the operation of other microwave components.

In this manuscript, the design and implementation of a miniaturized dual-band WPD is demonstrated. Firstly a dual-band WPD is designed at $1 \mathrm{GHz}$ and $2.6 \mathrm{GHz}$ frequency band using three quarter wavelength transmission line sections. To reduce the circuit size all the transmission lines are replaced by a dual transmission lines, as a result of which significant size reduction of $65 \%$ is achieved. To improve the reflection coefficient and isolation performance of the circuit, the second dual transmission line section is replaced by a cascaded $\pi$-shape transmission line and the rest of the design remains unchanged. Therefore, the overall circuit area is reduced by $62 \%$ compared with reference dual-band WPD. The reflection coefficient and 
isolation performance are improved by $15 \mathrm{~dB}$ and $2 \mathrm{~dB}$, respectively, at lower frequency band. The isolation performance is improved by $10 \mathrm{~dB}$ at the upper frequency band. The proposed design is simulated using HFSS full wave EM simulator and fabricated on Arlon substrate with dielectric constant $\varepsilon_{\mathrm{r}}$ of 2.2 , thickness $h$ of $0.787 \mathrm{~mm}$ and loss tangent of 0.0009 .

\section{Dual-Band Wilkinson Power Divider and its Miniaturization}

\subsection{Design of Dual-Band Wilkinson Power Divider}

Figure 1 shows the layout of the reference (Ref.) dualband WPD composed of three transmission line (TL) sections [13]. To satisfy the dual band response, electrical lengths at $f_{1}$ and $f_{2}$ should follow (1-2), where $R$ is the frequency ratio. Therefore, electrical length $\theta_{\mathrm{f} 1}$ is $50^{\circ}$ calculated from (1) with respect to the lower frequency band of $1 \mathrm{GHz}$ for the frequency ratio $\left(R=f_{1} / f_{2}\right)$ of 2.6.For the miniaturization point of view, we choose the average electrical length $\theta_{\mathrm{f}}$ for all the transmission line sections to design dual-band WPD. The values of the characteristic impedances $\left(Z_{1}, Z_{2}\right.$ and $\left.Z_{3}\right)$ and the comparison between physical lengths corresponding to $\theta_{\mathrm{f} 1}$ and $\theta_{\mathrm{f} 2}$ of three TL sections are shown in Tab. 1. From the table it is clear that in both the cases physical length is the same. The load impedances at each port are $Z_{0}=50 \Omega$ and isolation resistance is $100 \Omega$.

$$
\begin{gathered}
\theta_{f 1}=\frac{\pi}{1+R}, \\
\theta_{\mathrm{f} 2}=\frac{R \pi}{1+R} .
\end{gathered}
$$

The optimized design parameters are tabulated in Tab. 2. The simulated S-parameters response of the ref. dual-band WPD is shown in Fig. 2. From Fig. 2 it is found that output at port 2 and port $3\left(S_{21}\right.$ and $\left.S_{31}\right)$ is $-3.5 \mathrm{~dB}$ with reflection coefficient $S_{11}<-25 \mathrm{~dB}$ and isolation between the output ports $>19 \mathrm{~dB}$ at lower frequency $1.03 \mathrm{GHz}$.

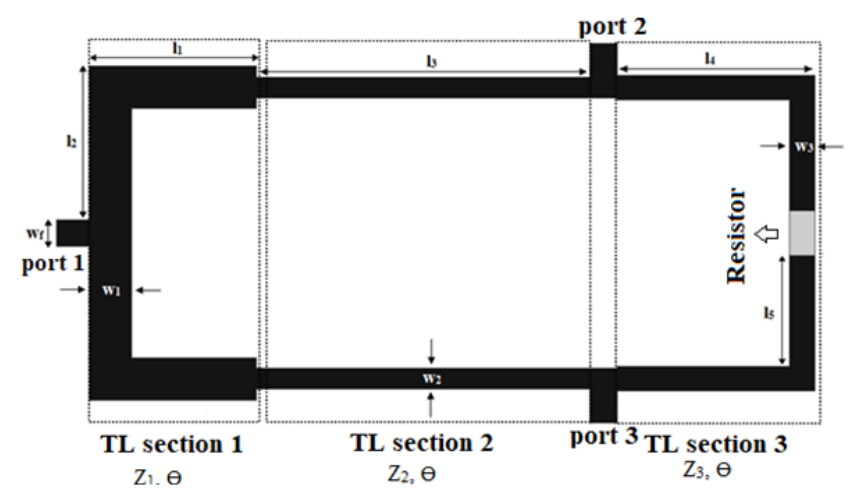

Fig. 1. Layout of the ref. dual-band WPD.

\begin{tabular}{|c|c|c|}
\hline $\begin{array}{c}\text { Characteristic } \\
\text { impedance }(\boldsymbol{\Omega})\end{array}$ & $\begin{array}{c}\text { Physical lengths (PL) } \\
\text { w. r. } \mathbf{t} \\
\boldsymbol{\theta}_{\mathrm{f} 1}=\mathbf{5 0 d e g}\end{array}$ & $\begin{array}{c}\text { PL w. r. t } \\
\boldsymbol{\theta}_{\mathrm{f}}=\left(\boldsymbol{\theta}_{\mathrm{f1}}+\boldsymbol{\theta}_{\mathrm{r} \mathbf{2}}\right) / \mathbf{2}=\boldsymbol{\pi} / \mathbf{2}\end{array}$ \\
\hline $\mathrm{Z}_{1}=36.4$ & $30.05 \mathrm{~mm}$ & $30.06 \mathrm{~mm}$ \\
\hline $\mathrm{Z}_{2}=58.6$ & $30.67 \mathrm{~mm}$ & $30.67 \mathrm{~mm}$ \\
\hline $\mathrm{Z}_{3}=50.3$ & $30.5 \mathrm{~mm}$ & $30.46 \mathrm{~mm}$ \\
\hline
\end{tabular}

Tab. 1. Dimension of the reference dual-band WPD.

\begin{tabular}{|l|c|c|c|c|c|c|c|c|}
\hline Parameters & $\boldsymbol{l}_{\mathbf{1}}$ & $\boldsymbol{l}_{\mathbf{2}}$ & $\boldsymbol{l}_{\mathbf{3}}$ & $\boldsymbol{l}_{\mathbf{4}}$ & $\boldsymbol{l}_{\mathbf{5}}$ & $\boldsymbol{W}_{\mathbf{1}}$ & $\boldsymbol{W}_{\mathbf{2}}$ & $\boldsymbol{W}_{\mathbf{3}}$ \\
\hline Value(mm) & 13.8 & 15 & 30 & 17.7 & 12 & 3.8 & 1.9 & 2.4 \\
\hline
\end{tabular}

Tab. 2. Design parameters of the reference dual-band WPD.

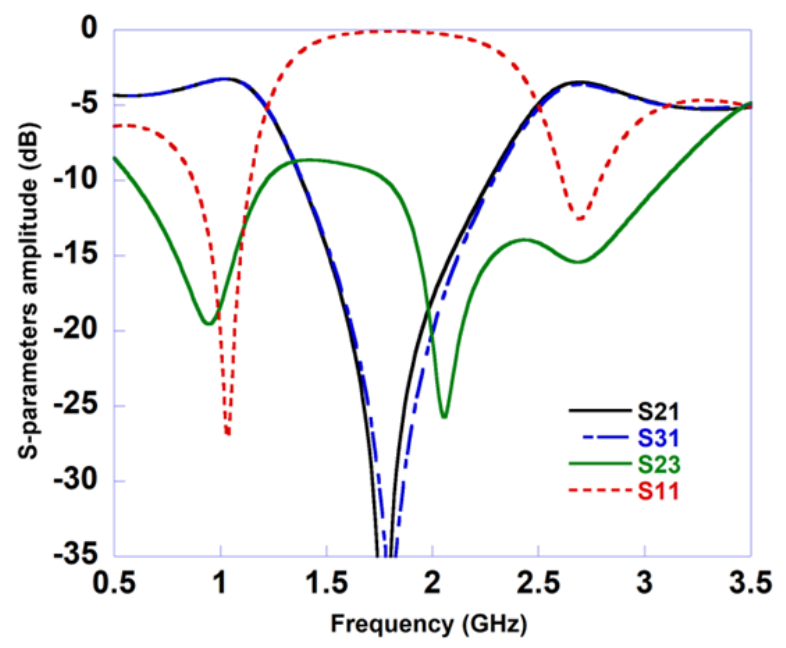

Fig. 2. S-parameter responses of the ref. dual-band WPD.

Similarly, the output at port 2 and 3 is $-3.6 \mathrm{~dB}$ with reflection coefficient and isolation $<-10 \mathrm{~dB}$ and $>18 \mathrm{~dB}$, respectively, at the upper frequency $2.6 \mathrm{GHz}$. The phase differences between the output ports are $0.5^{\circ}$ and $0.8^{\circ}$ at the lower and upper frequency band, respectively.

\subsection{Miniaturization of Dual-Band WPD Using Dual Transmission Line (TL)}

Figure 1 shows a dual-band WPD composed of three TL sections resulting in a large circuit size. In order to reduce the overall size, all the $\lambda / 4$-TLs are replaced by dual TL, namely designed 1 . In the dual TL, single $\lambda / 4$ TL of the initial design is split into a two parallel TL's structure as shown in Fig. 3. Here, $Z_{\mathrm{a}}, Z_{\mathrm{b}}, \theta_{\mathrm{a}}$, and $\theta_{\mathrm{b}}$ are defined as the characteristic impedances and the electrical lengths of dual TL's, respectively. Here $\theta\left(90^{\circ}\right)$ is the electrical length of single TL and the transmission matrix (ABCD parameter)

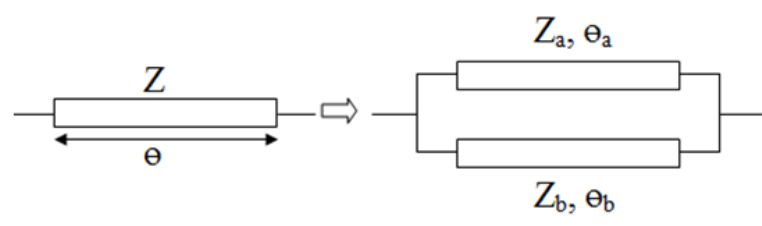

Fig. 3. Equivalent model of single TL with dual TL. 
is written in (3). Similarly ABCD matrixes are written for both line ' $a$ ' and ' $b$ ' in (4-5). The expression for the characteristic impedances and the electrical lengths are obtained from (3), (4), (5) and given in (6-8) [22]. From (6), (7) it is clear that, if the electrical length is to be chosen smaller, the impedance becomes higher which is to some extent difficult to fabricate. Therefore equal impedance is taken for simplicity and the electrical lengths are maintained as $\theta_{\mathrm{a}}<\theta=90^{\circ}<\theta_{\mathrm{b}}$ and $\theta_{\mathrm{a}}+\theta_{\mathrm{b}}=\pi$ in order to have compact size. Therefore, this dual transmission lines are composed of two high impedance lines with different electrical lengths. Out of these two lines, the longer one $\theta_{\mathrm{b}}$ is meander in shape to reduce the circuit area. Using the design equations of (6-7), the variation of characteristic impedances of dual TL as a function of $\theta_{\mathrm{a}}$ is shown in Fig. 4, for three TL sections having characteristic impedances $(Z)$ of $36.4 \Omega, 58.6 \Omega$, and $50.3 \Omega$, respectively.

$$
\begin{gathered}
{\left[\begin{array}{cc}
A & B \\
C & D
\end{array}\right]_{\theta}=\left[\begin{array}{cc}
0 & \mathrm{j} Z \\
\mathrm{j} Y & 0
\end{array}\right],} \\
{\left[\begin{array}{cc}
A_{\mathrm{a}} & B_{\mathrm{a}} \\
C_{\mathrm{a}} & D_{\mathrm{a}}
\end{array}\right]_{\text {line1 }}=\left[\begin{array}{cc}
\cos \theta_{\mathrm{a}} & \mathrm{j} Z_{0} \sin \theta_{\mathrm{a}} \\
\mathrm{j} Y_{\mathrm{a}} \sin \theta_{\mathrm{a}} & \cos \theta_{\mathrm{a}}
\end{array}\right],} \\
{\left[\begin{array}{cc}
A_{\mathrm{b}} & B_{\mathrm{b}} \\
C_{\mathrm{b}} & D_{\mathrm{b}}
\end{array}\right]_{\text {line2 }}=\left[\begin{array}{cc}
\cos \theta_{\mathrm{b}} & \mathrm{j} Z_{0} \sin \theta_{\mathrm{b}} \\
\mathrm{j} Y_{\mathrm{a}} \sin \theta_{\mathrm{b}} & \cos \theta_{\mathrm{b}}
\end{array}\right],} \\
Z_{\mathrm{a}}=Z \frac{\cos \theta_{\mathrm{b}}-\cos \theta_{\mathrm{a}}}{\sin \theta_{\mathrm{a}} \cos \theta_{\mathrm{b}}}, \\
Z_{\mathrm{b}}=-Z \frac{\cos \theta_{\mathrm{b}}-\cos \theta_{\mathrm{a}}}{\sin \theta_{\mathrm{a}} \cos \theta_{\mathrm{b}}}, \\
\frac{Z_{\mathrm{a}}}{Z_{\mathrm{b}}}=-\frac{\tan \theta_{\mathrm{b}}}{\tan \theta_{\mathrm{a}}}
\end{gathered}
$$

In design 1 a dual TL is used instead of conventional line. Therefore electrical lengths of dual TL, $\theta_{\mathrm{a}}$ and $\theta_{\mathrm{b}}$ are chosen as $45^{\circ}$ and $135^{\circ}$, respectively for transmission line section 1 and 3 . The corresponding characteristic impedances

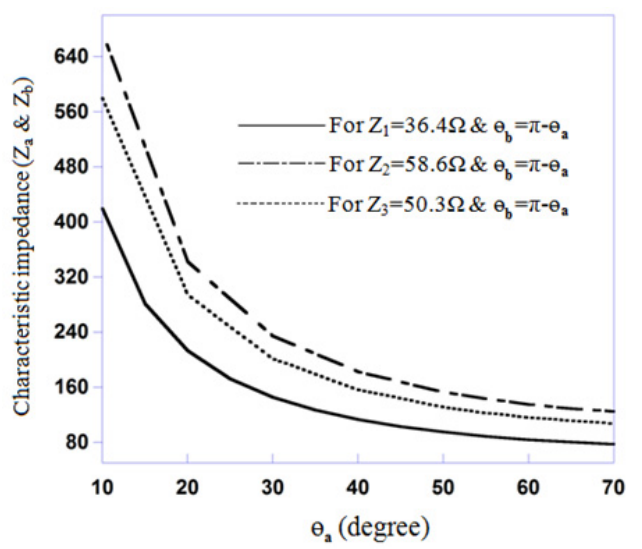

Fig. 4. Design curve of dual TL as function of $\theta_{\mathrm{a}}$ for the proposed design.

\begin{tabular}{|c|c|c|c|c|c|c|c|c|}
\hline Parameters & $\mathbf{l}_{\mathbf{1}}$ & $\mathbf{l}_{\mathbf{2}}$ & $\mathbf{a}$ & $\mathbf{b}$ & $\mathbf{l}_{\mathbf{3}}$ & $\mathbf{c}$ & $\mathbf{d}$ & $\mathbf{h}$ \\
\hline Value(mm) & 10 & 6.8 & 8.5 & 1.82 & 20 & 5.74 & 5 & 8.2 \\
\hline Parameters & $\mathbf{l}_{\mathbf{4}}$ & $\mathbf{l}_{5}$ & $\mathbf{g}$ & $\mathbf{f}$ & $\mathbf{W}_{\mathbf{1}}$ & $\mathbf{W}_{\mathbf{2}}$ & $\mathbf{W}_{\mathbf{3}}$ & $\mathbf{i}$ \\
\hline Value(mm) & 9.6 & 6.3 & 9.1 & 1.56 & 0.66 & 0.37 & 0.28 & 2.2 \\
\hline Parameters & $\mathrm{S}_{1}$ & $\mathrm{~S}_{2}$ & $\mathrm{~W}_{\mathrm{f}}$ & $\mathrm{l}_{\mathrm{f}}$ & $\mathrm{e}$ & & & \\
\hline Value(mm) & 0.5 & 1 & 2.4 & 4 & 4.8 & & & \\
\hline
\end{tabular}

Tab. 3. Optimized parameters of design 1 .

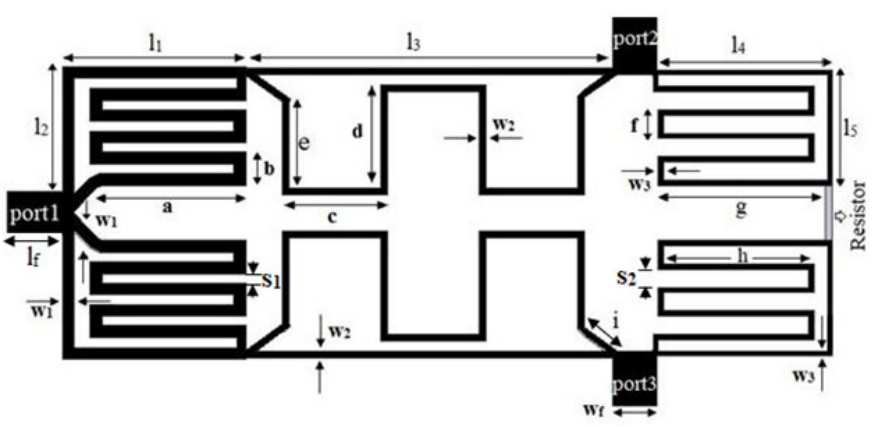

Fig. 5. Layout of design 1.

$\left(Z_{\mathrm{a}}\right.$ and $Z_{\mathrm{b}}$ ) are calculated from equations (6-7), where $Z$ is taken as $36.4 \Omega$ for TL section 1 and $50.3 \Omega$ for TL section 3 , therefore $Z_{\mathrm{a}}=Z_{\mathrm{b}}=103.5 \Omega$ and $\mathrm{Z}_{\mathrm{a}}=\mathrm{Z}_{\mathrm{b}}=142.2 \Omega$, respectively. Similarly for TL section 2 , the electrical lengths of dual TL, $\theta_{\mathrm{a}}$ and $\theta_{\mathrm{b}}$ are chosen as $65^{\circ}$ and $115^{\circ}$, respectively and the corresponding characteristic impedances $Z_{\mathrm{a}}=\mathrm{Z}_{\mathrm{b}}=129.3 \Omega$ for $Z=58.6 \Omega$. The optimized designed parameters are tabulated in Tab. 3 and the layout of design 1 is shown in Fig. 5.

\subsection{Performance Improvement of Miniatur- ized Dual-Band WPD Using Cascade $\pi$-shaped Transmission Line (TL)}

To improve the reflection coefficient as well as isolation performances of the design ' 1 ' at both the frequency bands, dual transmission line of section 2 is replaced by cascade $\pi$-shaped TL. Dual transmission line consists of two lines having different electrical lengths with high impedance. Out of the two lines in design 1, the longer line is meandered in shape to reduce the circuit area. The meandered section increases the number of discontinuity by bending and the coupling between the close bended lines increases. Any kinds of microstrip discontinuity (bend, gap and step) in the line generate surface waves that degrade the overall performances of the circuits. In order to minimize the discontinuity as well as coupling between the closed bended lines, the dual transmission line is replaced by cascaded $\pi$-shaped transmission line as a second transmission line section, namely design 2 . The performances are improved due to minimizing the number of discontinuities caused by dual transmission line. A cascaded $\pi$-shape transmission line consists of two series transmission lines 


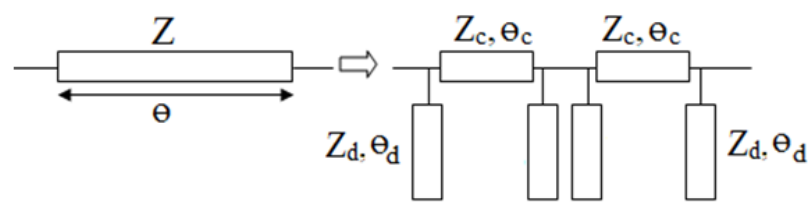

Fig. 6. Conventional line and its equivalent cascaded $\pi$-shape TL.

of characteristic impedance $Z_{\mathrm{c}}$, electrical length $\theta_{\mathrm{c}}$ and four shunt open stubs of characteristic impedance $Z_{\mathrm{d}}$, electrical length $\theta_{\mathrm{d}}$. The equivalent transmission line model of cascaded $\pi$-shape and conventional transmission line are shown in Fig. 6. The transmission matrix (ABCD) of quarter wavelength TL is equated with the ABCD matrix of cascaded $\pi$-shape TL in order to find the characteristic impedances and electrical lengths of line. The ABCD-matrix of quarter wavelength section and proposed TL are given by (3), (9). By evaluating (3) and (10), $Z_{\mathrm{c}}$ and $Z_{\mathrm{d}}$ can be solved as (12), (13) [21]. Equations (12), (13) are used to find the characteristics impedances of cascaded $\pi$-shape transmission line by properly choosing the electrical length of the series and shunt open stub of the proposed TL. The characteristic impedances $\left(Z_{\mathrm{c}}\right.$ and $\left.Z_{\mathrm{d}}\right)$ of the lines are evaluated from (12), (13) where $Z$ is taken as $58.6 \Omega$ and the electrical lengths $\left(\theta_{\mathrm{c}}\right.$ and $\left.\theta_{\mathrm{d}}\right)$ are selected as $20^{\circ}$ and $40^{\circ}$ in order to achieve miniaturization, respectively for $K=1.5$ and therefore $Z_{\mathrm{c}}=123 \Omega$ and $Z_{\mathrm{d}}=70 \Omega$. Once impedance and electrical lengths of series and shunt lines are known, the width and length of the series line and open stubs are easily obtained by using well know microstrip line equation. Finally, the optimized design parameters are tabulated in Tab. 4.

$$
\begin{gathered}
A B C D_{\pi}=\left[\begin{array}{ll}
1 & 0 \\
Y_{\mathrm{d}} & 1
\end{array}\right] \times\left[\begin{array}{cc}
\cos \theta_{\mathrm{c}} & \mathrm{j} Z_{\mathrm{c}} \sin \theta_{\mathrm{c}} \\
\frac{\mathrm{j} \sin \theta_{\mathrm{c}}}{Z_{\mathrm{c}}} & \cos \theta_{\mathrm{c}}
\end{array}\right] \times\left[\begin{array}{cc}
1 & 0 \\
Y_{\mathrm{d}} & 1
\end{array}\right] \\
{\left[\begin{array}{ll}
A & B \\
C & D
\end{array}\right]_{\mathrm{TL}}=A B C D_{\pi} \times A B C D_{\pi}} \\
Y_{\mathrm{d}}=\frac{\mathrm{j} \tan \theta_{\mathrm{d}}}{Z_{\mathrm{d}}} \\
\left.Z \begin{array}{l}
Z_{\mathrm{c}}=\frac{Z_{\mathrm{d}}}{\sin 2 \theta_{\mathrm{c}}-2 K \sin ^{2} \theta_{\mathrm{c}} \tan \theta_{\mathrm{c}}} \\
Z_{\mathrm{d}}=Z\left(3 M^{2} N+\left(\sin 2 \theta_{\mathrm{c}}\right) / K-6 K L M N^{2}\right. \\
-2 L^{2} N+2 K^{2} L^{2} N^{2}+M N
\end{array}\right)
\end{gathered}
$$

where $L=\sin \theta_{\mathrm{c}}, M=\cos \theta_{\mathrm{c}}, N=\tan \theta_{\mathrm{d}}, K=Z_{\mathrm{c}} / Z_{\mathrm{d}}$.

Layout of the proposed power divider (design 2) and its LC equivalent circuit are shown in Fig. 7(a) to 7(c), respectively. The LC equivalent of microstrip steps, open end, gap, and junction as presented in [2] are used to draw equivalent circuit of the proposed power divider. The reactive elements corresponding to the geometrical parts of the proposed design is shown in Fig. 7(b); where $L_{1 \mathrm{a}}, L_{1 \mathrm{~b}}, L_{3 \mathrm{a}}, L_{3 \mathrm{~b}}$

\begin{tabular}{|l|c|c|c|c|c|c|c|c|}
\hline Parameters & $\mathbf{l}_{\mathbf{1}}$ & $\mathbf{l}_{\mathbf{2}}$ & $\mathbf{a}$ & $\mathbf{b}$ & $\mathbf{l}_{\mathbf{3}}$ & $\mathbf{c}$ & $\mathbf{d}$ & $\mathbf{l}_{\mathbf{4}}$ \\
\hline Value(mm) & 9.3 & 8 & 5.3 & 2.32 & 14 & 7.6 & 2.1 & 8 \\
\hline Parameters & $\mathbf{l}_{\mathbf{5}}$ & $\mathbf{l}_{\mathbf{6}}$ & $\mathbf{e}$ & $\mathbf{f}$ & $\mathbf{W}_{\mathbf{1}}$ & $\mathbf{W}_{\mathbf{2}}$ & $\mathbf{W}_{\mathbf{3}}$ & $\mathbf{W}_{\mathbf{4}}$ \\
\hline Value(mm) & 8 & 8.8 & 6.2 & 1.5 & 0.66 & 0.37 & 1 & 0.35 \\
\hline Parameters & $\mathrm{S}_{1}$ & $\mathrm{~S}_{2}$ & $\mathrm{~g}$ & $\mathrm{~W}_{\mathrm{f}}$ & $\mathrm{l}_{\mathrm{f}}$ & & & \\
\hline Value(mm) & 1 & 1.5 & 2 & 2.4 & 4 & & & \\
\hline
\end{tabular}

Tab. 4. Dimensions of the proposed power divider.

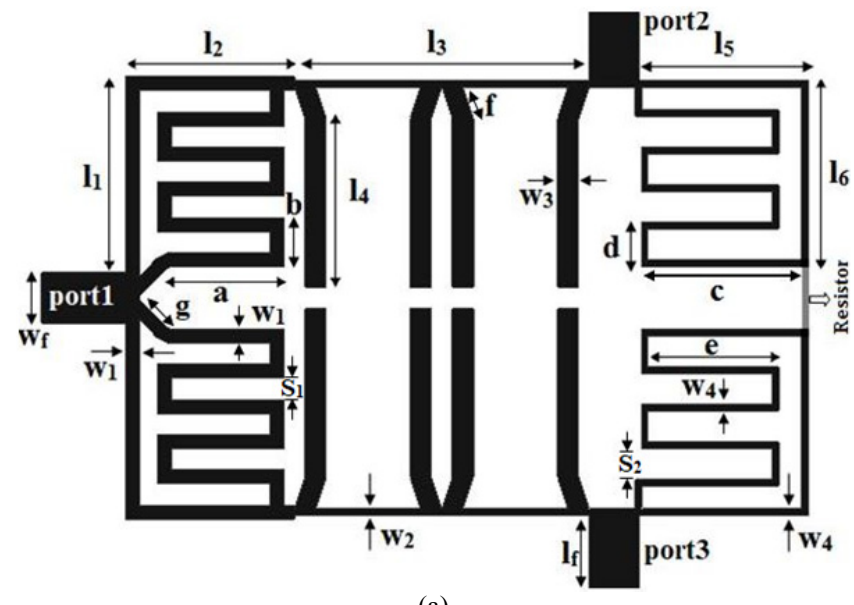

(a)

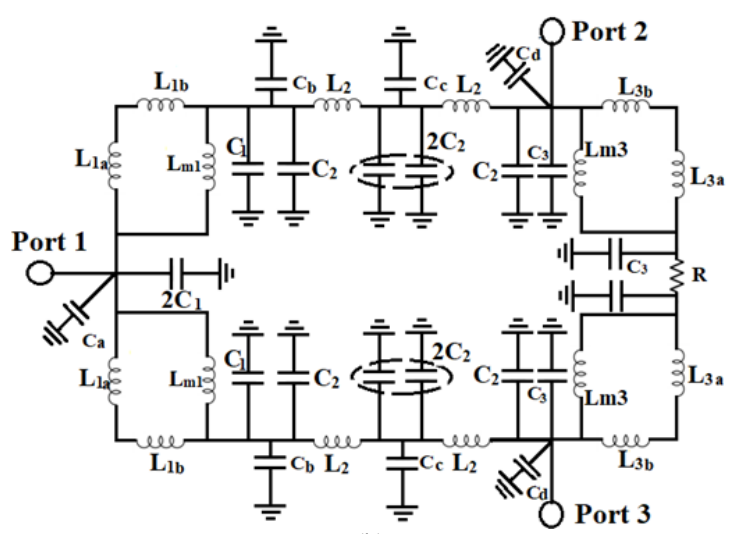

(b)

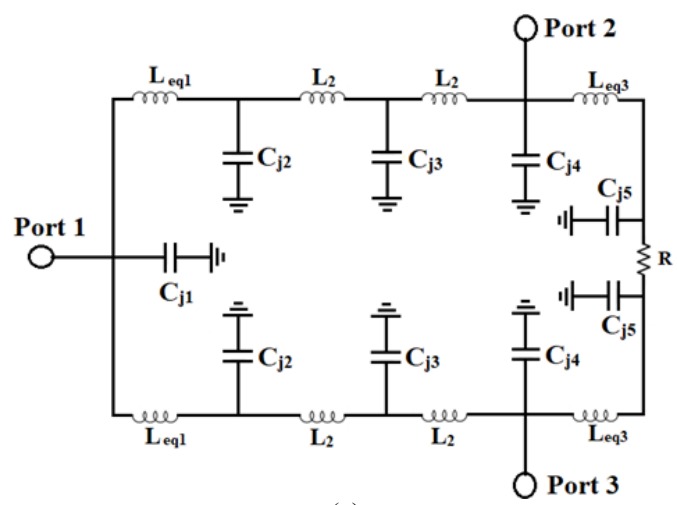

(c)

Fig. 7. The proposed dual-band Wilkinson power divider: (a) Microstrip layout, (b) LC equivalent circuit, (c) simplified LC equivalent circuit. 
the inductance of inverted $\mathrm{L}$ shaped lines of section 1 and 3, $L_{\mathrm{m} 1}, L_{\mathrm{m} 3}$ are the inductance of meandered line of section 1 and 3. The capacitance $C_{1}$ and $C_{3}$ are due to line joints between straight line and meandered line with respect to the ground. In addition $L_{2}$ and $C_{2}$ are the inductance and the capacitance of cascaded $\pi$-shaped line. $C_{\mathrm{a}}, C_{\mathrm{b}}, C_{\mathrm{c}}$, and $C_{\mathrm{d}}$ represent the junction capacitance between the sections and terminals of the power divider with respect to ground. Figure 7(c) depicts the simplified LC equivalent circuit of Fig. 7(b). In Fig. 7(c), $L_{\text {eq1 }}$ and $L_{\text {eq } 3}$ are the equivalent inductances of section 1 and section 3 , respectively, whereas $C_{\mathrm{j} 1}, C_{\mathrm{j} 2}, C_{\mathrm{j} 3}, C_{\mathrm{j} 4}$ and $C_{\mathrm{j} 5}$ are the equivalent junction capacitances. The component values of the simplified LC equivalent circuit are obtained, where $L_{\text {eq } 1}=3.5 \mathrm{nH}$, $L_{\mathrm{eq} 3}=4.7 \mathrm{nH}, \quad L_{2}=3.8 \mathrm{nH}, \quad C_{\mathrm{j} 1}=3 \mathrm{pF}, \quad C_{\mathrm{j} 2}=2.29 \mathrm{pF}$, $C_{\mathrm{j} 3}=1.1 \mathrm{pF}, C_{\mathrm{j} 4}=2.73 \mathrm{pF}$, and $C_{\mathrm{j} 5}=1.3 \mathrm{pF}$.

\section{Simulation and Experimental Results}

The proposed dual-band WPD is designed and fabricated to operate at $1 \mathrm{GHz}$ and $2.6 \mathrm{GHz}$. The proposed designs are as follows: design 1 consists of a dual transmission line and design 2 consists of a cascaded $\pi$-shape TL and dual TL for miniaturization of the ref. dual-band WPD. Therefore, the proposed technique provides a substantial miniaturization of around $65 \%$ for design 1 and $62 \%$ for design 2 without degrading the other performance factor of the ref. power divider. Figure 8 shows the simulated S-parameters response for both design 1 and 2 and compared with ref. dual-band WPD. From Fig. 8 it is clear that the simulated response of the proposed power divider (design 2) provides the good response as compared to the design 1 and ref. dual band WPD for both the frequency bands. The reflection coefficient and isolation performance are improved by $15 \mathrm{~dB}$ and $2 \mathrm{~dB}$ compared to design 1 at lower frequency band, respectively. Similarly, the isolation performance is improved by $10 \mathrm{~dB}$ at the upper frequency band. Finally, simulated S-parameter responses of design 1 and 2 are shown in Fig. 9. From Fig. 9(a) it is clear the operating frequencies are $1.2 \mathrm{GHz}$ and $2.5 \mathrm{GHz}$ for design 1. Figure 9(b) shows the electromagnetic (EM) simulation and simplified LC equivalent circuit simulation results of the proposed power divider (design 2). From this figure it is clearly seen that the circuit simulation of the proposed WPD has two transmission bands near $1.05 \mathrm{GHz}$ and $2.6 \mathrm{GHz}$, whereas EM simulation operated at $1.1 \mathrm{GHz}$ and $2.55 \mathrm{GHz}$. In this way, one can justify the validity of the circuit model.

The photographs of the fabricated unit are shown in Fig. 10 for both design 1 and 2, respectively. An Agilent vector network analyzer is used to test the performance of the fabricated power divider. The measured S-parameter responses are compiled with the simulated response for both design 1 and 2 to ensure that the proposed dual-band WPD exhibits good performance in the real time environment as shown in Fig. 11 and 12, respectively. From Fig. 11 fractional bandwidth (FBW) is found to be $20 \%$ for

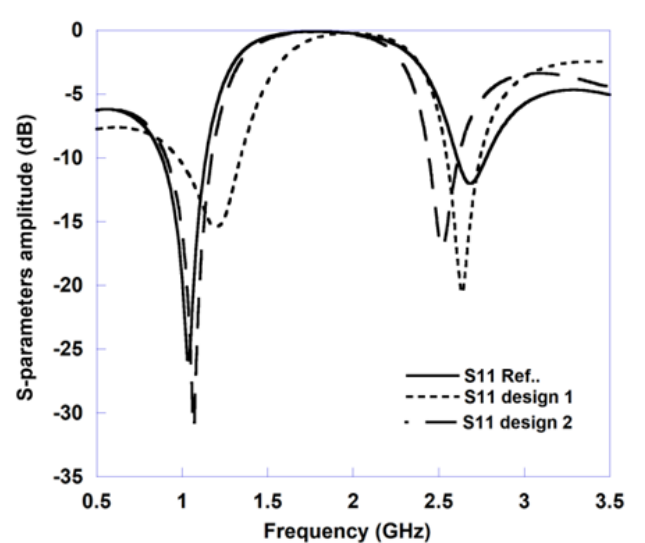

(a)

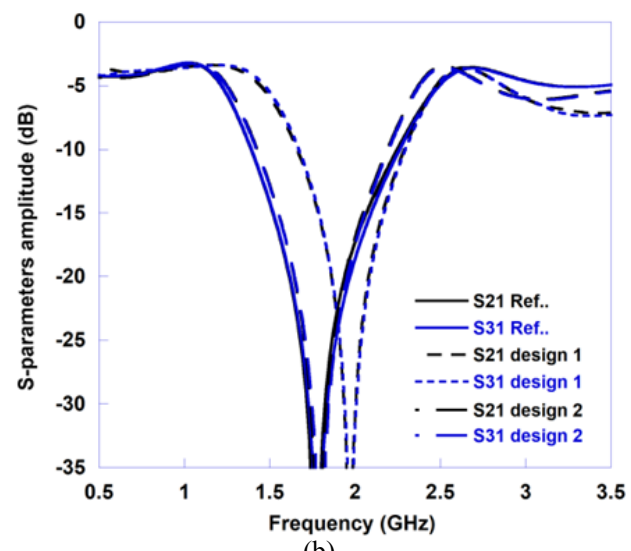

(b)

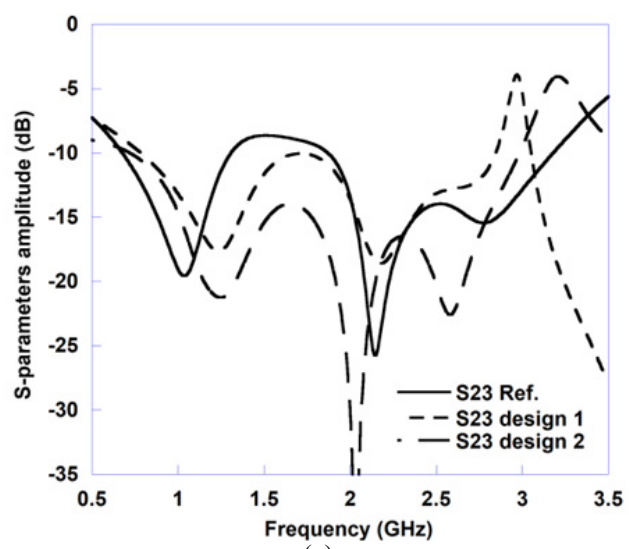

(c)

Fig. 8. Comparisons of simulated S-parameter responses of design 1 and design 2, with ref. dual-band WPD: (a) $S_{11}$, (b) $S_{21} \& S_{31}$, (c) $S_{23}$.

the insertion loss of $(3.45 \pm 0.3) \mathrm{dB}$ at the output ports with reflection coefficient better than $-15 \mathrm{~dB}$ and isolation $>15 \mathrm{~dB}$ for the lower frequency of $1.25 \mathrm{GHz}$. Similarly, for the upper frequency of $2.5 \mathrm{GHz}, \mathrm{FBW}$ is found to be $17 \%$ for the insertion loss of $(3.5 \pm 0.3) \mathrm{dB}$ with reflection coefficient $<-15 \mathrm{~dB}$ and isolation $>14 \mathrm{~dB}$.

From Fig. 12 the FBW is found to be $21 \%$ for the insertion loss of $(3.4 \pm 0.3) \mathrm{dB}$ at the output ports with reflection coefficient better than $-15 \mathrm{~dB}$ and isolation better than $15 \mathrm{~dB}$ for the lower frequency of $1.2 \mathrm{GHz}$. Similarly, for the upper frequency of $2.6 \mathrm{GHz}, \mathrm{FBW}$ is found to be $15 \%$ for the insertion loss $(3.4 \pm 0.3) \mathrm{dB}$ with reflection coefficient better than $-15 \mathrm{~dB}$ and isolation better than $20 \mathrm{~dB}$. 


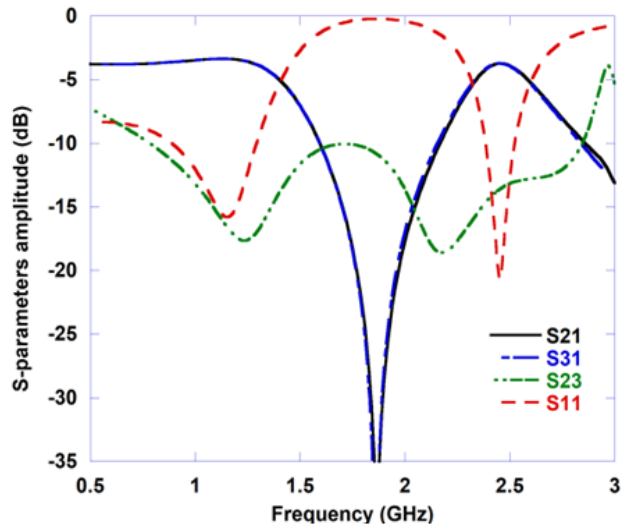

(a)

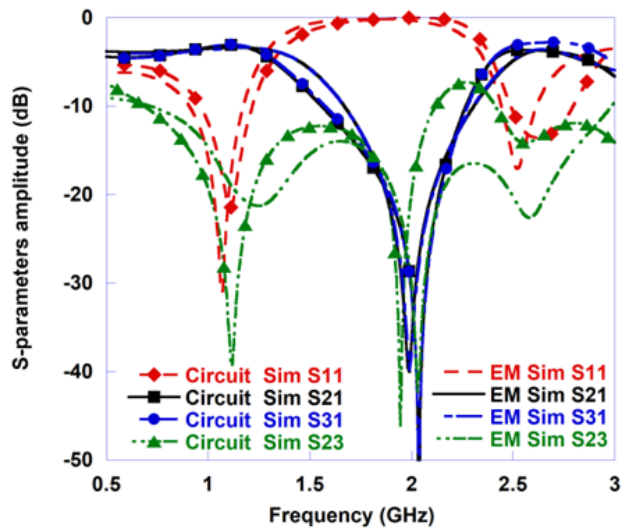

(b)

Fig. 9. Simulated S-parameter responses (a) design 1, (b) design 2 .

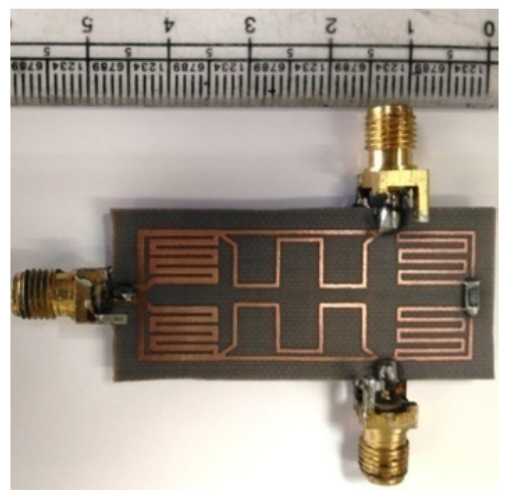

(a)

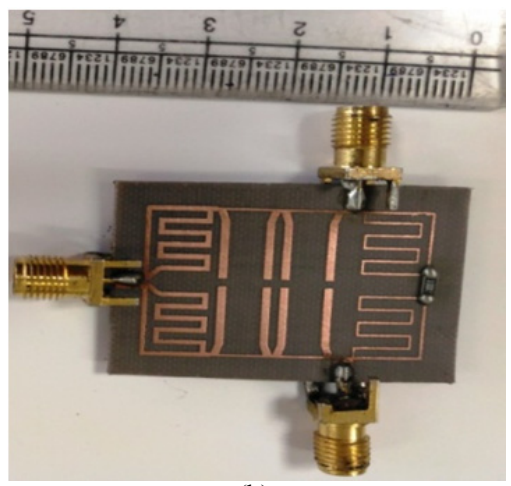

(b)

Fig. 10. Photograph of the fabricated unit of the proposed dualband WPD: (a) design 1, (b) design 2.

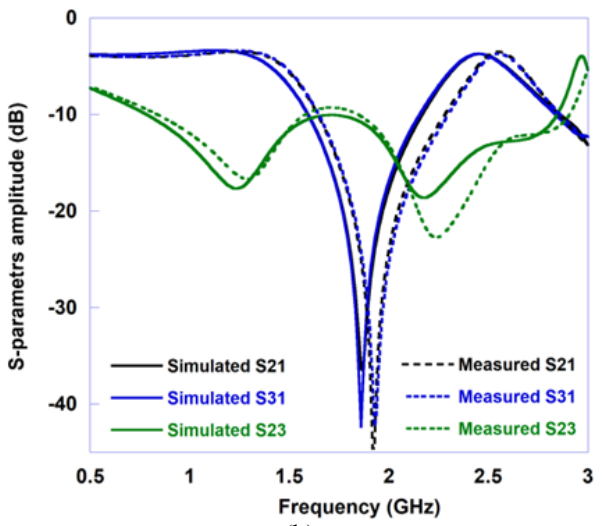

(b)

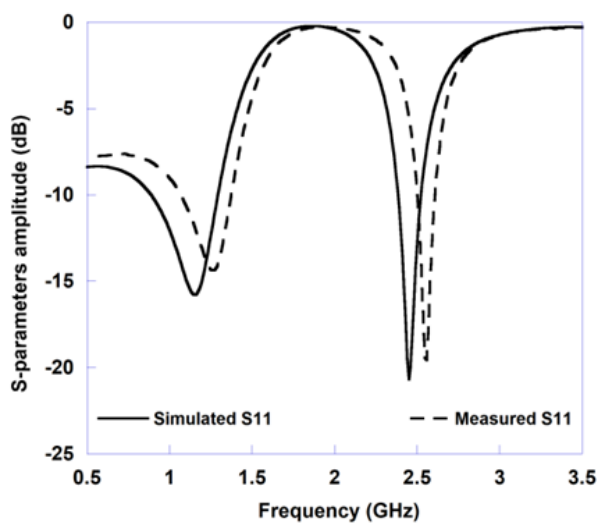

(c)

Fig. 11. Measured and simulated S-parameter responses of design 1: (a) $\mathrm{S}_{21}, \mathrm{~S}_{31}, \mathrm{~S}_{23}$, (b) $\mathrm{S}_{11}$.

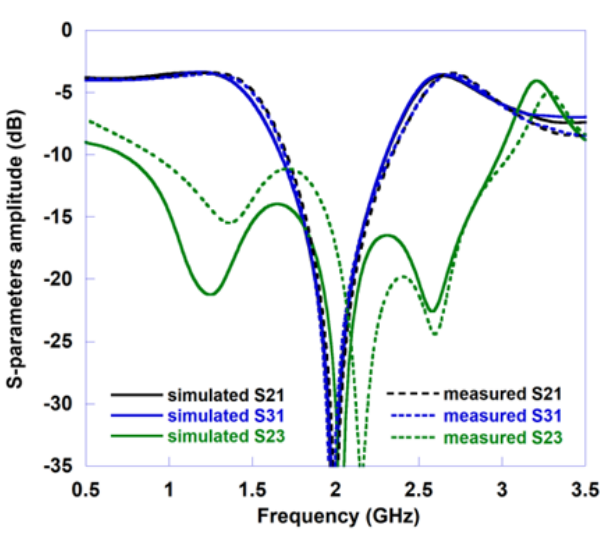

(a)

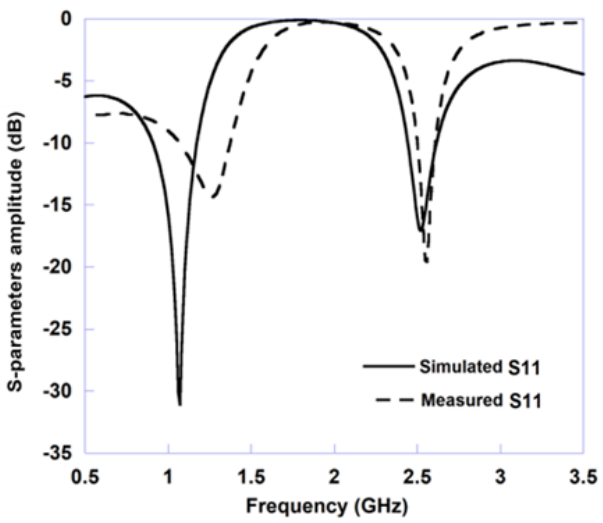

(b)

Fig. 12. Measured and simulated S-parameter responses of design 2: (a) $\mathrm{S}_{21}, \mathrm{~S}_{31}, \mathrm{~S}_{23}$, (b) $\mathrm{S}_{11}$. 


\begin{tabular}{|c|c|c|c|c|c|}
\hline Ref., Year & $f_{\mathbf{1}}, \boldsymbol{f}_{\mathbf{2}}(\mathbf{G H z})$ & $\left.\boldsymbol{S}_{\mathbf{2 1}}=\boldsymbol{S}_{\mathbf{3 1}} \mathbf{( d B}\right)$ & $\boldsymbol{S}_{\mathbf{2 3}} \mathbf{( d B )}$ & $\boldsymbol{S}_{\mathbf{1 1}} \mathbf{( d B )}$ & Area \\
\hline$[\mathbf{1 3}], \mathbf{2 0 1 4}$ & $1.0,2.6$ & $-3.2,-3.3$ & $-30,-30$ & $-28,-28$ & $0.29 \lambda_{\mathrm{g}} \times 0.13 \lambda_{\mathrm{g}}$ \\
\hline$[\mathbf{1 4}], \mathbf{2 0 1 6}$ & $1.0,3.0$ & $-3.2,-3.15$ & $-27,-35$ & $-30,-30$ & $0.28 \lambda_{\mathrm{g}} \times 0.12 \lambda_{\mathrm{g}}$ \\
\hline$[\mathbf{2 3}], \mathbf{2 0 1 6}$ & $1.57,2.89$ & $-3.9,-4.1$ & $<-21,<-25$ & $-19,-17$ & $0.38 \lambda_{\mathrm{g}} \times 0.28 \lambda_{\mathrm{g}}$ \\
\hline$[\mathbf{2 4}], \mathbf{2 0 1 7}$ & $0.9,3.5$ & $-3.2,-3.6$ & $-26,-24$ & $-16,-31$ & $0.17 \lambda_{\mathrm{g}} \times 0.15 \lambda_{\mathrm{g}}$ \\
\hline [25], 2017 & $0.9,2.1$ & $-3.2,-3.4$ & $-35,-25$ & $<-15,<-15$ & $0.26 \lambda_{\mathrm{g}} \times 0.20 \lambda_{\mathrm{g}}$ \\
\hline Design 1 & $\mathbf{1 . 2 , 2 . 5}$ & $\mathbf{- 3 . 5 , - 3 . 4}$ & $\mathbf{- 1 6 , - 1 4}$ & $\mathbf{- 1 6 , - 2 1}$ & $\mathbf{0 . 1 9} \lambda_{\mathrm{g}} \times \mathbf{0 . 0 7} \lambda_{\mathrm{g}}$ \\
\hline Design 2 & $\mathbf{1 . 1 , 2 . 5 5}$ & $\mathbf{- 3 . 5 , - 3 . 4}$ & $\mathbf{- 1 7 , - 2 4}$ & $\mathbf{- 3 1 , - 1 8}$ & $\mathbf{0 . 1 4} \lambda_{\mathrm{g}} \times \mathbf{0 . 0 9} \lambda_{\mathrm{g}}$ \\
\hline
\end{tabular}

Tab. 5. Comparisons of the proposed dual-band WPD with existing ones.

The phase difference (PD) between the output ports are $0.6^{\circ}$ and $0.2^{\circ}$ at the lower and upper frequency band, respectively.

The dual-band property along with other characteristics of the proposed design is also compared with some other works and the comparison is tabulated in Tab. 5. In comparison, it is found that the design 1 is $3 \%$ more compact than design 2 , but the isolation and return loss performance is poor compared to design 2. So, in terms of overall performance factors (return loss, isolation, and insertion loss) design 2 is better compared to design 1, despite a little bit miniaturization.

\section{Conclusion}

A compact dual-band Wilkinson power divider (WPD) is designed based on cascaded $\pi$-shape and dual transmission lines. The proposed design is occupied only $38 \%$ circuit area compared to ref [13]. It is to be further noted that despite the miniaturization, no other performance factors are degraded. Herein lies the advantage of the proposed design over the existing design, although the dual line is a little bit complicated. Since the proposed structure is very compact thus making it suitable to be used in compact and sophisticated microwave systems.

\section{Acknowledgments}

This work is supported by the Ministry of Electronics and Information Technology (MeitY) for providing financial support under Visvesvaraya $\mathrm{PhD}$ scheme.

\section{References}

[1] POZAR, D. M. Microwave Engineering. 3rd ed. New York: Wiley, 2007. ISBN: 978-8126510498

[2] HONG, J. S. Microstrip Filters for RF/Microwave Applications. New York: Wiley, 2001. DOI: 10.1002/0471221619
[3] SRISATHIT, S., CHONGCHEAWCHAMNAN, M., WORAPISHET, A. Design and realization of dual-band $3 \mathrm{~dB}$ power divider based on two-section transmission-line topology. Electronics Letters, 2003, vol. 39, no. 9, p. 723-724. DOI: 10.1049/EL:20030483

[4] WU, L., YILMAZ, H., BITZER, T., et al. A dual-frequency Wilkinson power divider: for a frequency and its first harmonic. IEEE Microwave and Wireless Components Letters, 2005, vol. 15, no. 2, p. 107-109. DOI: 10.1109/LMWC.2004.842848

[5] LEI WU, ZENGGUANG SUN, YILMAZ, H., et al. A dual-frequency Wilkinson power divider. IEEE Transactions on Microwave Theory and Techniques, 2006, vol. 54, no. 1, p. 278-284. DOI: 10.1109/TMTT.2005.860300

[6] AVRIllon, S., PEle, I., CHOUSSEAud, A., TOUTAIN, S. Dual-band power divider based on semi loop stepped-impedance resonators. IEEE Transactions on Microwave Theory and Techniques, 2003, vol. 51, no. 4, p. 1269-1273. DOI: 10.1109/TMTT.2003.809667

[7] CHENG, K. K. M., WONG, F. L. A new Wilkinson power divider design for dual band application. IEEE Microwave and Wireless Components Letters, 2007, vol. 17, no. 9, p. 664-666. DOI: 10.1109/LMWC.2007.903454

[8] ZHANG, H., XIN, H. Designs of dual-band Wilkinson power dividers with flexible frequency ratios. In IEEE MTT-S International Microwave Symposium Digest. Atlanta (USA), 2008, p. 1223-1226. DOI: 10.1109/MWSYM.2008.4633279

[9] CHENG, K. K. M., LAW, C. A novel approach to the design and implementation of dual-band power divider. IEEE Transactions on Microwave Theory and Techniques, 2008, vol. 56, no. 2, p. 487-492. DOI: 10.1109/TMTT.2007.914629

[10] PARK, M. J., LEE, B. Wilkinson power divider with extended ports for dual-band operation. Electronics Letters, 2008, vol. 44, no. 15, p. 916-917. DOI: 10.1049/EL:20080821

[11] LI, X., GONG, S. X., YANG, L., YANG, Y. J. A novel Wilkinson power divider for dual-band operation. Journal of Electromagnetic Waves and Applications, 2009, vol. 23, p. 395-404. DOI: $10.1163 / 156939309787604346$

[12] LEE, J. H., JEON, I. S., CHO, Y. H., et al. Design of dual-band power divider using shunt open-stubs with enhanced attenuation characteristics. In Asia Pacific Microwave Conference Proceedings. Kaohsiung (Taiwan), 2012, p. 1199-1120. DOI: 10.1109/APMC.2012.6421868

[13] WU, G., YANG, L., ZHOU, Y., XU, Q. Wilkinson power divider design for dual-band applications. Electronics Letters, 2014, vol. 50, no. 14, p. 1003-1005. DOI: 10.1049/EL.2014.0741

[14] ZAFAR BEDAR KHAN, ZHAO HUILING, ZHANG YIMIN. Simplified approach for design of dual-band Wilkinson power 
divider with three transmission line sections. Microwave and Optical Technology Letters, 2016, vol. 58, p. 2374-2377. DOI: 10.1002/MOP.30052

[15] YANG, J., GU, C., WU, W. Design of novel compact coupled microstrip power divider with harmonic suppression. IEEE Microwave and Wireless Components Letters, 2008, vol. 18, no. 9, p. 572-574. DOI: 10.1109/LMWC.2008.2002444

[16] EOM, D. J., KAHNG, S. T. Fully printed dual-band power divider miniaturized by CRLH phase shift lines. ETRI Journal, 2013, vol. 35, p. 150-153. DOI: 10.4218/ETRIJ.13.0212.0131

[17] LIN, C. M., SU, H. H., CHIU, J. C., et al. Wilkinson power divider using microstrip EBG cells for the suppression of harmonics. IEEE Microwave and Wireless Components Letters, 2007, vol. 17, no. 10, p. 700-702. DOI: 10.1109/LMWC.2007.905595

[18] ZHANG, F., LI, C. F. Power divider with microstrip electromagnetic band gap element for miniaturization and harmonic rejection. Electronics Letters, 2008, vol. 44, p. 422-423. DOI: 10.1049/EL:20083693

[19] WOO, D. J., LEE, T. K. Suppression of harmonics in Wilkinson power divider using dual-band rejection by asymmetric DGS. IEEE Transactions on Microwave Theory and Techniques, 2005, vol. 53, no. 6, p. 2139-2144. DOI: 10.1109/TMTT.2005.848772

[20] HAYATI, M., ABDIPOUR, A., ABDIPOUR, A. A Wilkinson power divider with harmonic suppression and size reduction using high low impedance resonator cells. Radioengineering, 2015, vol. 24 , no. 1, p. 137-141. DOI: 10.13164/re.2015.0137

[21] BARIK, R. K., KUMAR, K. V. P., KARTHIKEYAN, S. S. A compact wideband harmonic suppressed $10 \mathrm{~dB}$ branch line coupler using cascaded symmetric pi sections. Microwave and Optical Technology Letters, 2016, vol. 58, no. 7, p. 1610-1613. DOI: $10.1002 / \mathrm{MOP} .29870$

[22] TANG, C. W., CHEN, M. G., TSAI, C. H. Miniaturization of microstrip branch-line coupler with dual transmission lines. IEEE Microwave and Wireless Components Letters, 2008, vol. 18, no. 3 , p. 185-187. DOI: 10.1109/LMWC.2008.916798

[23] ZHANG, G., WANG, J., ZHU, L., WU, W. Dual-band filtering power divider with high selectivity and good isolation. IEEE Microwave and Wireless Components Letters, 2016, vol. 26, no. 10, p. 774-776. DOI: 10.1109/LMWC.2016.2604878

[24] MAKTOOMI, M. A., HASHMI, M. S. A performance enhanced port extended dual-band Wilkinson power divider. IEEE Access, 2017, vol. 5, p. $11832-11840 . \quad$ DOI: 10.1109/ACCESS.2017.2715283

[25] SHAO, C., LI, Y., CHEN, J. X. Compact dual-band microstrip filtering power divider using T-junction structure and quarterwavelength SIR. Electronics Letters, 2017, vol. 53, no. 6, p. 434-436. DOI: 10.1049/EL.2017.0182

\section{About the Authors...}

Mukesh KUMAR $(* 1989)$ received the B.Tech. degree in Electronic and Telecommunication Engineering from the Biju Patnaik University of Technology, Rourkela, Orissa in 2011, and the M.Tech. degree in Electronics and Communication Engineering from the National Institute of Technology, Durgapur in 2015. He is currently pursuing the Ph.D. degree in Microwave Engineering with the Electronics and Tele-Communication Engineering Department, Indian Institute of Engineering Science and Technology, Shibpur, Howrah, India. His current research interests include microwave planer circuits, power divider, couplers.

Susanta Kumar PARUI $(* 1965)$ received the B.Sc. degree in Physics and the B. Tech degree in Radio Physics and Electronics from the University of Calcutta in 1987 and 1990, respectively. He has done the Master degree in Microwave Communication Engineering from the Bengal Engineering College, India in 1993. From 1993 to 2000, he worked as an Instrument Engineer. Since 2000, he is associated with the Department of Electronics and Telecommunication Engineering, Bengal Engineering and Science University, India and presently holds the post of Senior Lecturer. His current research interests include the planar circuits, filters, antenna elements and electromagnetic band gap structures.

Santanu DAS $(* 1968)$ received the B.E. degree in Electronic and Telecommunication Engineering from the Bengal Engineering College in 1989 and the M.E degree in Microwave Engineering from the Jadavpur University, Calcutta in 1992. He obtained the Ph.D. (Engineering) degree in the year 1998 from the Jadavpur University. As Lecturer in Electronics and Telecommunication Engineering, he joined the department of the Bengal Engineering and Science University in 1998 and presently holds the post of a Professor at the same department. His current research interests include the microstrip circuits, antenna elements and arrays, FSS and defected ground structures. He is a life member of the Institution of Engineers, India. 